\title{
Extrahepatic Bile Duct Rhabdomyosarcoma
}

National Cancer Institute

\section{Source}

National Cancer Institute. Extrahepatic Bile Duct Rhabdomyosarcoma. NCI Thesaurus. Code C5860.

A malignant mesenchymal tumor with skeletal muscle differentiation, arising from the extrahepatic bile ducts. 